\title{
A NATIVIDADE DE CRISTO NA LITERATURA PORTUGUESA: TEXTOS E CONTEXTOS
}

Paula Almeida Mendes $\star$

https://orcid.org/0000-0002-5748-6350

Como citar este artigo: MENDES, P. A. A Natividade de Cristo na literatura portuguesa: textos e contextos. Todas as Letras - Revista de Lingua e Literatura, São Paulo, v. 23, n. 3, p. 1-14, set./dez. 2021. DOI 10.5935/1980-6914/eLETDO2114806

Submissão: setembro de 2021. Aceite: outubro de 2021.

Resumo: Tendo como pano de fundo a Natividade de Cristo, este artigo procura chamar a atenção para as várias e diversas releituras e reatualizações que esta narrativa foi conhecendo na literatura portuguesa, mostrando como a Bíblia se configura como um macrotexto.

Palavras-chave: Natividade. Cristo. Literatura portuguesa. Espiritualidade. Bíblia.

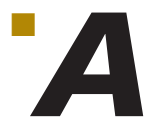

Natividade de Cristo ocupou, desde o cristianismo primitivo, um muito significativo destaque na moldura das práticas espirituais e devotas, declinando-se na literatura, na iconografia e na estatuária, através de múltiplas releituras, revisitações e reatualizações (FRYE, 2002; CARVALHO, 2005). Com efeito, a importância desta narrativa e a vitalidade da figura do Menino Jesus, no contexto da história da salvação, destacam-se, como é sabido, no Evangelho de Lucas (2:6-21), mas, muito especialmente, nos evangelhos apócrifos que compõem o ciclo da Infância, nomeadamente no Protoevangelho de Tiago e no Pseudoevangelho de São Mateus (SANTOS OTERO, 1963), na 
medida em que, tentando colmatar as lacunas dos textos canónicos, foram introduzindo no relato alguns detalhes que muito contribuíram para nutrir a curiosidade dos fiéis e cristalizar a devoção, enformada por matizes de afetividade e de doçura, em torno do Filho de Deus (LA ROCCA, 2007). A literatura religiosa produzida ao longo da Antiguidade tardia concederia também uma significativa atenção ao nascimento de Cristo - a título de exemplo, lembremos a Homília sobre o Natal de Santo Efrém ou os sermões sobre o Natal de Santo Agostinho -, configurando uma moldura que alcançará maior consistência e relevo durante a Idade Média. Por outro lado, importará não perder de vista que os textos apócrifos foram, em larga medida, influenciando, ao longo da época medieval, a composição de várias hagiografias e legendários que difundiram várias dimensões relacionadas com o nascimento de Cristo: assim o testemunha a Legenda áurea, recopilada por Jacques de Voragine, que recupera, em algumas passagens relacionadas com a Natividade e a Infância do Salvador, vários topoi que encontramos no Pseudoevangelho de São Mateus (VORAGINE, 1967, p. 65-73). Por outro lado, a emergência de uma "tendência" que, a partir da Baixa Idade Média, foi enfatizando a importância da Humanidade de Cristo no domínio da espiritualidade, na esteira de várias místicas, muito contribuiu para a valorização da Infância de Cristo. Várias místicas medievais, como Santa Gertrudes de Helfta, que embalava e enfaixava a imagem do Menino Jesus, desenvolveram práticas espirituais que se polarizavam em torno da devoção ao Deus Menino (CARVALHO, 1981; CIRLOT; GARÍ, 2008). Porém, é importante não esquecer que os mendicantes deram também um relevante contributo nesse sentido, através da recriação do presépio, em Greccio, que conheceu um significativo sucesso no contexto da espiritualidade europeia (ALMEIDA, 1983).

O tema da Natividade de Cristo encontraria também uma ampla receção na moldura do teatro medieval de matriz religiosa e litúrgica. A Visitatio sepulchri, representada na Páscoa, estaria na génese da produção da Visitatio praesepe, que, associada à celebração do Natal e escorada nos Evangelhos de Lucas (2:1-20) e de Mateus (2:1-12), constituiria uma espécie de díptico formado pelo Officium pastorum e Ordo Stellae, em que se destacava a visita dos pastores e dos Reis Magos ao presépio. Esta tradição encontraria ainda eco, nas primeiras décadas do século XVI, em alguns autos de matriz devocional produzidos por Gil Vicente: disso são exemplo o Auto pastoril castelhano (1502), o Auto dos Reis Magos (1503), o Auto da fé (1510?), o Auto dos quatro tempos (1511?), o Auto da sibila Cassandra (1513?), o Auto do purgatório (1518), o Auto pastoril português (1523), o Auto da feira (1527) e o Auto de Mofina Mendes (1534) (BERNARDES; CAMÕES, 2018). No domínio literário, o Natal encontra também expressão ao nivel da poesia: a título de exemplo, lembremos que Mestre André Dias (Ordem de São Bento [OSB]) dedica cinco laudes a este episódio bíblico. De molde a ilustrá-lo, evoquemos esta loa composta pelo religioso beneditino, que sublinha o papel redentor do Salvador e a sua natureza humana:

O boom Christo Jhesu he nado,

e humanado,

por salvar toda a gente,

que era perdida e degradada,

por o primeiro nosso parente.

Nado he o senhor Jhesu Christo,

por todo o poboo seer remiido, 
de nos muyto pecadores

que eramos degradados

de seermos seus servidores,

e por perdoar nossos errores

veo e naçeo em este mundo triste

e de todo muy faleçente.

Rep. O boom Christo Jhesu he nado.

Huum fremoso lilyo, branco e vermelho,

nado he em este mundo, pera a nos dar boom consselho,

e por fugirmos do Inferno muyto profundo,

porem teve por bem de viir,

e por nos morte soffryr,

a qual era muyto danosa a nos primeiramente.

Rep. O boom Christo Jhesu he nado.

Em Bethleem he nado,

o senhor da virgem pura,

o qual foy profetizado

por a sancta scriptura,

el remidor e pyedoso assaz,

nos de em esta sua festa muyto solaz,

que o louvemos e a el cantemos,

muyto gloriosamente.

Rep. O boom Christo Jhesu he nado (DIAS, 1951, p. 91-92).

A literatura de espiritualidade, nos tempos pós-Trento, dedicaria uma significativa atenção à Natividade de Cristo, inscrevendo-se, deste modo, na moldura da ofensiva contrarreformista que, através de uma vasta produção textual, favorecida pelo surgimento da imprensa e constituída por obras de tipologia diversa, muito investira no disciplinamento dos comportamentos e das práticas devocionais dos fiéis ${ }^{1}$. Atendendo a este enquadramento, lembremos as Meditações e Homílias sobre alguns Mysterios da Vida de Nosso Redemptor e sobre alguns Lugares do Sancto Evangelho que fez o Serenissimo e Reverentissimo Cardeal D. Anrique \&c. por sua Particular Deuação (1564), que conheceu várias edições e traduções ${ }^{2}$.

A meditação que inaugura a obra, intitulada "Do nascimento do nosso Redemptor", centra-se, como o próprio título indica, no referido acontecimento histórico, que, para o autor, condiciona todo o devir da humanidade, projectando-se em uma perspectiva escatológica. O cardeal D. Henrique destaca, sobretudo, a ambiência de pobreza em que nasceu Cristo: com efeito, ao vir ao mundo nessas circunstâncias para condenar em seu nascimento "a nossa

Sobre essa vasta produção e difusão do livro religioso na Época Moderna, veja-se, para o caso português: Fernandes (2000 p. 187-193), Santos (2000, p. 125-130), Santos (2013, p. 143-158) e Mendes (2017).

2 Da primeira edição desta obra, impressa em Évora, em caracteres góticos, não se conhecem exemplares. Este texto seria reeditado em Lisboa, em 1574 e em 1577. A obra foi traduzida para o latim, por Fr. António de Sena (Ordem dos Pregadores [OP]), por instância de Francisco Giraldes, embaixador de Castela na corte inglesa, tendo-lhe acrescentado o Tratado dos Tres votos essenciaes da Religião, escrito por Fr. Humberto de Romanis (O.P.) (Lovanii apud Servatium Sassenium, 1575). Os jesuítas de Évora fariam nova tradução deste texto, que saiu com o título seguinte: Meditationes, \& homiliae in aliqua mysteria Salvatoris, \& in nonnulla Evangelii loca, quas sibi privatim conscripsit Serenissimus, \& Reverendissimus Cardinalis D. Henricus potentissimi, ac invictissimi Emmanuelis quondam Portugallia Regis filius (Olyssipone apud Franciscum Correa, 1576). Nesta edição, foram também incluídas as "Meditaçoens sobre a Magnificat e Oração Dominical", que foram traduzidas em latim por D. Jerónimo Osório. Sobre esta obra, veja-se Carvalho (1990, p. 271-279) e Mendes (2017, p. 176-188). 
soberba vãa, a falsa riqueza, \& a enganosa deleytaçam" (D. HENRIQUE, 1577, f. 6 v), o autor equaciona a conceção do contemptus mundi, que se traduz no anseio de despojamento e fuga das coisas mundanas (DELUMEAU, 1983, p. 15-40). De resto, o autor sublinha que

Desse presepio logo em nascendo no mundo nos ensinais, \& dais hum tam proveitoso exemplo. Manifestam também as vossas lagrimas, que começais logo a padescer, \& offerecer trabalhos, deshonras, \& tormentos por nós a vosso Padre: \& que esta he vossa vinda ao mũdo pera nos reconciliar com elle, \& accẽder tanto em vosso amor nossas vontades, \& desejo de vos seruir, que em tudo vos sigamos, \& procuremos vossa gloria, \& alcançar a paz que oje cantauam os anjos (D. HENRIQUE, 1577, f. 7-r-7 v.).

Cristo apresenta todos os traços do humano - e repare-se como a sua imagem está já tão distante do Cristo Pantocrator da Alta Idade Média -, mas o cardeal acentua, especialmente, o seu papel de Redentor:

E a vos meu menino IESV, homem \& Deos, mais trespassa o amor que os tormẽtos, pois com tamanho desejo vos offereceis a elles, \& os sofreis por nosso bem. Pois tudo isto he nosso, assi do nascimento como da morte, \& o que passastes, \& fizestes, he pera nosso ensino, tudo vos torno a offerecer, \& a mim mesmo, para me apurardes na fragoa do fogo desse amor, \& me alumiardes com a clara luz de vossa doctrina, \& exemplo, \& assi seguir com vossa graça (quanto me for possiuel) vossa charidade, obediencia, paciencia, humildade, \& pobreza (D. HENRIQUE, 1577, f. 8 r.-8 v.).

A “Oração ao Minino Iesu posto no presépio" retoma alguns aspetos do texto que o antecede, exaltando a imagem do Menino Jesus, enquanto mediador entre Deus e os homens, e apelando à dimensão afectiva e ternurenta que aquela encerra, em sintonia com os rumos que vinham sendo trilhados, na esteira da Devotio moderna. É uma das composições incluídas neste volume que nos merece maior atenção, na medida em que nos poderá ajudar a compreender em que moldes se desenvolveu e projetou o misticismo de D. Henrique. Como já sublinhou Joaquim O. Bragança (1994, p. 317), "com o nascimento de Jesus Cristo começa um mundo novo, a renovação do homem e, por ele, do universo". O cardeal sublinha a dimensão da humanidade de Cristo, traduzida nas circunstâncias em que ocorreu o Seu nascimento e Paixão, fundamentais para a redenção do género humano. D. Henrique, como realçou Bragança (1994, p. 317), apresenta uma visão cósmica do mistério da Redenção, "[...] que consiste em 'fazer o homem novo, com que se renovam todas as cousas [...] se acabarem de todo na universal Ressurreição".

O cardeal D. Henrique $(1577$, f. 9 r.) acentua o papel redentor do Menino Deus:

Quam inteiramente compris, meu minino Iesu, Redẽptor \& renovador de todas as cousas, com esta vossa nova vinda ao mundo, o que diz Sant Ioão Euangelista no Apocalypse, que vos ouuio, Faço tudo nouo. Gue cousa mais noua, que fazerse Deos homem?.

Neste sentido, o cardeal almeja a sua própria renovação, visando ultrapassar a sua condição de pecador, a partir da renovação universal em Cristo: 
E pois tudo se renova não fique o meu coração, \& minha alma enueterada nas misérias, \& custumes velhos, pois esta he vossa morada, segundo diz sancto Augustinho, que vos não pode achar se não em seu coração: cõ esta vossa summa pureza querei que o meu se apure, \& renoue, pera despejado das immundicias \& desordẽs dos vicios da vida, soberba rica \& deliciosa, \& de todos os mais, volo poder offerecer: \& pera nelle remedeardes o frio, pobreza, \& dureza que padeceis nesse presepio (D. HENRIQUE, 1577, f. $10 \mathrm{r}-10 \mathrm{v}$ ).

É bem sabido como o Maneirismo foi acentuando uma mundividência pessimista e agónica da condição humana que, no caso português, foi amplificada pelas consequências do desastre de Alcácer-Quibir, que conduziram à perda da independência do reino, na sequência do desaparecimento de D. Sebastião. Em uma moldura marcada pela consciência da mesquinhez humana - aliás, é recorrente, em vários textos produzidos por esses tempos, o tema do homo homini lupus -, condicionado pela inexorável marcha do tempo e pela efemeridade da vida, não nos deverá causar estranheza que se defenda que ao homem só resta, se pretende encontrar algum refrigério na vida terrena, adotar um ideal de vida pautado pelo contemptus mundi e voltar-se para Deus, na esperança de alcançar a salvação eterna. Tendo em conta este enquadramento, não nos deverá causar estranheza que a Natividade de Cristo, enquanto momento crucial e simbólico no sentido da redenção da humanidade, seja convocada em algumas composições poéticas produzidas ao longo daquele complexo período histórico e cultural (AGUIAR E SILVA, 1971, p. 347-348). Deste modo, a celebração do Natal, em moldes poéticos, tem como protagonistas autores como Diogo Bernardes, que dedicou um soneto, "À noite de Natal", incluído nas Várias rimas ao Bom Jesus (1594):

Ó noite santa e clara, inda que escura te vê quem mais não ergue a fantesia, noite que mereceste, mais que odia. ver nascido Jesus da Virgem pura;

como se não tornou logo em brandura tua grande aspereza, noite fria, vendo teu Criador que padecia teu frio como humana creatura?

Como vos desatais, ó ventos, tanto? Porque vos derreteis, nuves, em água?

Tempo, que te não tornas mais sereno?

Se não sentis do Filho o tenro pranto, senti a dor da Mãe, senti a mágoa de o guardar de vós com palha e feno (BERNARDES, 2008, p. 149).

Baltasar Estaço, cónego da sé de Viseu, dedicaria, na sua obra Sonetos, canções, eglogas e outras rimas (1604), cinco sonetos à Natividade de Cristo (PIRES, 2010, p. 47-57): “Ao nascimento de amor" (ESTAÇO, 1604, f. 57 v), "Ao lume do sempiterno" (ESTAÇO, 1604, f. 57 v-58 r), "Às lágrimas do Menino Jesus" (ESTAÇO, 1604, p. 58 v-59 r), "Ao Menino Jesus Deus dos Céus" (ESTAÇO, 1604, p. 59 v-60 r) e "Ao Menino Jesus rei sem gente" (ESTAÇO, 1604, f. 60 v). A título de exemplo, lembremos a composição intitulada "Ao nascimento de amor": 
Que suave, que doce e branda história

Amor, para meu bem, inventa e traça!

Que grande glória hoje a Terra abraça,

Pois em seus braços tem ao Deus da glória!

Que grande prazer tem minha memória

De ver com quanta graça esconde a graça

Amor, pois em meu trajo a Deus disfarça,

Por poder festejar minha vitória.

De homem, sendo Deus, nasceis vestido,

Porque, vestindo Vós sua pobreza,

De quantas ele tem possa despir-se.

E sendo Deus, nasceis homem despido,

Porque, despindo Vós Vossa riqueza,

De quantas tendes Vós possa vestir-se.

A Natividade de Cristo mereceria também a atenção de Fr. Agostinho da Cruz. Da pena do religioso arrábido saíram os sonetos "À noite de Natal" e "À mesma noite". A composição "À noite de Natal" realça, sobretudo, a pobreza que enquadra o nascimento do Salvador:

Era noite de Inverno longa, e fria,

Cobria-se de neve e verde prado;

$O$ rio se detinha congelado,

Mudava a folha a cor, que ter soía.

Guando nas palhas de uma estrebaria,

Entre dous animais brutos lançado,

Por não ter outro lugar no povoado,

O Menino Jesus pobre jazia:

- Meu filho, meu amor, porque quereis

(Dizia sua Mãi) nesta aspereza

Acrescentar-me as dores, que passais?

Aqui nestes meus braços estareis;

Que vos força amor sofrer crueza,

O meu não pode agora sofrer mais (CRUZ, 1994, p. 62).

Por outro, não será despiciendo destacar a produção de textos que cruzam a devoção mariana com o mistério da Natividade, de que é exemplo a Liçam espiritual do nascimento de Christo Nosso Senhor, para a noute do Natal (1675) ${ }^{3}$ de Vasco Pires, que equaciona várias dimensões "corporizadas" pela Virgem: o seu papel enquanto "auogada dos pecadores", a sua virgindade perpétua ("Thalamo virginal da Senhora"), a sua maternidade divina, a sua pobreza ("E poys este Sapientissimo Minino vindo á terra, escolhe pera si o que he mays penoso em idade tam tenra, e que ser filho de hũa Mãy tam pobre, que escassamente tem hũns pobres paninhos em que o enuolua") (PIRES, 1675, p. 8). O autor louva também a pobreza do presépio - "Trono do Salamam verdadeyro, e Senhor dos

3 Essa obra foi reeditada no Compendio da Paixão de Christo, tirado das Meditações de Fr. Luís de Granada (Lisboa: João Galrão, 1676). 
Exercitos" -, concluindo com esta reflexão, não isenta de significados de várias naturezas:

E poys este Sapientissimo Minino vindo à terra, escolhe pera si o que he mays penoso em idade tam tenra, e quer ser filho de hũa Mãy tam pobre, que escassamente tem hũns pobres paninhos em que o inuolua; logo o melhor, e o mays acertado, que a seu exemplo se pode nesta vida escolher, he o mays penoso, $e$ menos delicioso pera o Corpo, e dizer o contrario he erro, engano, e desatino (PIRES, 1675, p. 8).

No domínio das devoções, no Portugal seiscentista e setecentista, merece também destaque a atenção que a figura do Menino Jesus conheceu, sobretudo nos meios monásticos e conventuais femininos: neste sentido, sobretudo nas "vidas" femininas, os autores realçam a particular ou privilegiada intimidade das biografadas com o Menino Jesus, que poderá estar relacionada com a difusão do modelo e da obra de Santa Gertrudes de Helfta, a partir de finais do século XVI, já bem estudada por José Adriano de Freitas Carvalho (CARVALHO, 1981). De resto, as religiosas confecionavam enxovais para ornar as imagens do Menino Jesus, prática que, em certa medida, parece assumir-se como uma alternativa encontrada por estas mulheres para expressarem uma afeição maternal, cuja concretização, devido à clausura e à opção pelo estado religioso, era inviável. Por outro lado, será importante não perder de vista o conjunto de textos poéticos, produzidos em sede monástica, que, efetivamente, atestam a devoção que muitas religiosas nutriam pelo Menino Jesus: a título de exemplo, lembremos o Memorial da Infância de Cristo (1639) de soror Maria Mesquita Pimentel (MORUJÃO, 2013, p. 532-564).

Em todo o caso, um olhar sobre a temática em torno da Natividade implicará, naturalmente, que não se percam de vista algumas obras que se inscrevem no veio da literatura hagiográfica ou biográfica devota, na medida em que refletem a vitalidade que a devoção ao Menino Jesus assumia nos espaços monásticos e conventuais (MARTINS, 1947, p. 565-581).

Fr. Manuel da Esperança, na segunda parte da História serafica da Ordem dos Frades Menores de S. Francisco na Provincia de Portugal (1666), relata-nos um extraordinário acontecimento, ocorrido no Natal, no mosteiro de Santa Clara da Guarda:

Era a noite do Natal, em que todas com devação festejavam a o Minino Jesu, nacido d'aquella hora em o portal de Belèm. Estava elle deitado em hum presepio pobre à imitação do outro, onde sua Mãe santissima primeiro o reclinou \& ainda qu tinha algum ornato, este era mui devoto, sem aparatos custosos, nem profanidades vans, das quaes se ofende muito o espirito Serafico. As freiras à sua roda, contemplando num mysterio taó alto de Deos vestir nossa carne pera nos endiozar, nos corações, \& nas almas o querião recolher. Hũa dellas (nã̃ lembra jà o seu nome) que andava mais solicita, morria de sentimento porque não achava flores, com as quaes lhe enramasse o berço, de que mostrava gostar seu infinito amor. E não podendo avellas nesta cidade da Guarda, cuberta então de neve, onde neste tempo reinaõ os rigores do inverno; nem com este impossivel se esfriou seu fervor.

Pelo que, magoada desta falta saïo do coro pera trazer da cozinha hũas brazas, nas quaes queimasse pastilhas; \& passando pelo claustro, achou na segunda 
quadra hũa roseira pequena; que d'antes não tinhão visto, cuberta toda de folhas, entressachadas de rosas. Notada a maravilha, com que Deos autorizava a devação do Presepio, cortarão o ornamento da miraculosa planta, \& com elle enfeitàrão o curioso retrato da lapinha de Belèm. Levantouse o Presepio, \& pera satisfazer â petição dos devotos, por elles se repartiraõ muitos dos ramos, \& rosas. Outros se depositàrão em hum cofre de Reliquias, que nem por isso se defenderão dos furtos da devação indiscreta. Não avia já no anno 1642, no qual eu examinei este caso, senão só hũa folhinha de rosa, \& hum raminho das folhas (ESPERANÇA, 1666, p. 333-334).

Por sua vez, a madre Helena da Cruz, como:

[...] devotissima do mysterio do Nacimento se prevenia, para elle em o Advento com os mais penosos exercícios, mais austera nos jejuns, mais rigorosa nas penitencias, mais frequente na oração, mas sem voz no silencio, fazendo neste tempo os seus retiros, e ali a leuava seu Esposo; a outra mais doce solidaõ aonde the fallaua ao ouvido, sem ruido de vozes, nem estrondo de palavras. Chegaua à noite de Natal taõ enternecida como quem em as prevençoens hauia empenhado todo o cabedal do coraçaõ para aquelle fogo. [...] Por muytas vezes vio em esta clara noite os Anjos da gloria animados, e vistidos de luzes. Em huma em que Deos a quis sublimar a mayor gloria, vio ao Menino que estava em a manjedoura, em carne, e desta forma sahio della, e se the poz em o regasso. Qual ficaria com este favor, sò o dirà quem o chega a experimentar. A noticia fique para todos, os sentimentos fiquem sò para ella, a quem o Menino, entre os seus braços disse: Queresme muyto? A reposta foy qual a pedia o amor, e qual a merecia a pergunta (CÉU, 1993, p. 159-160).

A propósito de soror Ambrósia do Monte Calvário, religiosa no mosteiro de Jesus, em Viana do Alentejo, conta-nos Jorge Cardoso, no Agiológio lusitano, que

[...] sempre co a consideração na Paixão de Christo; tam admirauel no silencio, que não consta o quebrasse algũa hora, \& a voz era tam summissa, que nem a si própria se ouuia; tam deuota dos sanctos Reis Magos, que a noite precedente a seu dia os ïa esperar muito cedo no Presepio: \& adormecendo hũa vez, passadas as horas costumadas, os sanctos Reis, que estimauão muito sua vigia, com estrondo de quem caminha em Dromedarios, a vierão despertar; acordou toda espauorida, foise ao Presepio pedirlhes perdão, publicando a vozes, que vira os sanctos Reis, cuidando, que todas auião logrado o mesmo fauor (CARDOSO, 1657, p. 37).

A temática polarizada em torno da Natividade de Cristo continuaria, ao longo dos séculos seguintes, a convocar a atenção de vários autores. Assim o atesta o conto "O Menino Jesus do Paraíso", de Fialho de Almeida, incluído em O pais das uvas (1893), que declina, efetivamente, o olhar acutilante deste autor, ao qual não escapam as consequências da exclaustração, iniciada em 1834. Joaquim Constâncio, o "Menino Jesus do Paraíso", narrador e protagonista da narrativa, conta-nos que uma jovem donzela, oriunda de Montemor-o-Novo, foi obrigada a ingressar no convento de Nossa Senhora do Paraíso de Évora, em 1826. No entanto,

[...] ao contrário do que se esperava, a freira nova, apenas entrada no mosteiro, pretextando doença, nunca mais abandonou a sua cela; comia pouco, teimava em não ver a luz do dia, de sorte que vivia às escuras, levando horas a dar 
gemidos que enterneciam a comunidade e pouco a pouco the foram criando lendas de martírio. Véspera de Natal, ao cair da noite, enquanto as monjas se afadigavam a engalanar a igreja, a cobrir os altares de flores e searinhas, e a dispor no claustro as grandes figuras de roda do presepe, os gritos e gemidos da desterrada exprimiam, lá do fundo da cela, um sofrimento excruciante [...]. A poder dos grandes rogos da criada, deixaram-lhe ir o Menino do presepe, pra que sua ama o vestisse, conforme promessa feita a Nossa Senhora (ALMEIDA, 1987, p. 188).

Nessa noite, os fiéis entram na igreja para ver e admirar o presépio,

[...] ao tempo em que já o capelão, de capa d'asperges, véu de ombros, tomara o menino do berço, para o dar a beijar aos circunstantes. Mas caiu de joelhos, fulminado: o menino Jesus mexia os braços e desatara a berrar como um cabrito! (ALMEIDA, 1987, p. 189).

Equacionar a problemática polarizada em torno da Natividade de Cristo, no contexto da espiritualidade, em Portugal do século XX, nomeadamente no domínio da poesia, implica considerar aspetos que se prendem não apenas com a larga tradição desta tipologia textual, mas também com outras dimensões que se ligam à indagação da existência de Deus, oscilando entre a crença e a não crença, assim como com a emergência de novas "confissões" na contemporaneidade (FERREIRA, 2001, p. 382-388). A moldura da espiritualidade no Portugal contemporâneo apresenta-se através de múltiplas manifestações que se declinam, de forma muito visivel e evidente, na literatura e, muito especialmente, na poesia (CHORÃO, 1984). O registo poético torna-se, assim, o espaço em que se problematizam questões que se prendem com a crença na existência de Deus, com a ausência ou a inexistência da esfera divina, a finitude da existência humana, a mortalidade e a imortalidade.

Parece-nos possivel afirmar que um profundo cristocentrismo traveja a produção e a estrutura de um conjunto muito significativo de poemas, ao longo do século XX, conferindo-lhe um "ritmo" calibrado pelo Evangelho e por outros textos que "glosaram" a Sagrada Escritura. Esta dimensão desenvolve-se em duas vertentes: a Infância do "Menino Deus" e a Paixão e Ressurreição de Cristo.

Na moldura da valorização do ciclo da Infância de Cristo, a devoção ao Natal e ao presépio plasma-se na poesia portuguesa do século XX, como o mostra o poema "Presépio", de Sebastião da Gama (1924-1952), incluído em Pelo sonho é que vamos (1953):

Nuzinho sobre as palhas,

nuzinho e em Dezembro!

Que pintores tão cruéis,

Menino, te pintaram!

O calor do seu corpo,

p'ra que o quer tua Mãe?

Tão cruéis os pintores!

(Tão injustos contigo,

Senhora!)

Só a vaca e a mula/com seu bafo te aquecem...

- Guem as pôs na pintura? (GAMA, 1953, p. 10). 
O mesmo autor, em outra composição poética intitulada "Em que se fala do Menino Jesus", incluída na obra Serra-Mãi (1945), evoca a faceta infantil de Cristo:

Fiz a maldade e olhei Jesus,

Ele baixou os olhos e còrou,

e toda a gente julgou

que quem fez a maldade foi Jesus.

E todos Lhe perdoaram...

- Obrigado, Menino! Mas agora/tira os olhos do bibe e vem brincar,

que eu prometo pra não Te ver córar,

já não fazer das minhas.

Anda jogar ao pé das flores, no chão,

comigo, às cinco pedrinhas...;

anda jogar, pra esqueceres

o preço do meu perdão... (GAMA, 1945, p. 53).

Por sua vez, António Corrêa d'Oliveira (1878-1960) dedicou também algumas composições à quadra da Natividade, incluídas na obra Redondilhas: "A estrelinha do Natal" (D'OLIVEIRA, 1948, p. 179), “A grutinha de Belém” (D'OLIVEIRA, 1948, p. 180), "A mais linda jumentinha” (D'OLIVEIRA, 1948, p. 181) e "Jesus, Maria, José” (D’OLIVEIRA, 1948, p. 182).

A vitalidade da temática da Natividade de Cristo continuou, ao longo dos séculos XX e XXI, a estimular a produção literária, mais concretamente sob a forma de antologias: assim o testemunham os Textos para o Natal, Cadernos F.A.O.J. (1979) ou Gloria in Excelsis Deo. Histórias Portuguesas de Natal (2003), organizadas por Vasco Graça Moura. No domínio da poesia, poderíamos ainda referir o Cancioneiro do Natal (1971), de David Mourão-Ferreira ou o Retábulo para um intimo Natal (1980), de António Manuel Couto Viana.

No domínio da prosa, o tema da Natividade de Cristo encontra também, no caso português, novas leituras e reactualizações. Disso é exemplo o conto "O outro Menino Jesus" (1968), de Luís Cajão. Evocando o contexto colonial contemporâneo, o autor narra as dificuldades profissionais vivenciadas por uma jovem médica, em São Tomé e Príncipe, destacando, muito especialmente, as circunstâncias em que ocorre o nascimento do filho da mulher de um pescador, na noite de Natal, estabelecendo um conjunto de semelhanças - a pobreza do lugar em que nasce o bebé, o facto de ter sido levado para o presépio que existia no hospital - com o episódio da Natividade de Cristo.

Tendo como cenário o Natal, o conto “Onde está o Menino Jesus?”, de Natália Correia, publicado em 1987, equaciona a questão da natureza de Cristo. Em todo o caso, importa sublinhar, como já o fez Marcello Sandmann (1994, p. 124), que o texto de Natália Correia instaura uma "ruptura", na medida em que a "narradora faz restrições à 'veracidade' de certa passagem da narrativa poética do heterônimo pessoano - àquela que se refere à fuga do menino Jesus do céu, antes de ir morar com o poeta. E esse suposto 'falseamento da verdade' que serve de pretexto para a nova narrativa": "Só há uma coisa em que esse poeta que guarda cabras, ou ovelhas ou lá que é se engana. É quando diz que o menino Jesus fugiu do céu". Desse modo, a narradora do conto evoca um episódio que ocorreu durante a sua infância, protagonizado por ela mesma e pelo Menino Jesus que se encontrava no presépio da sua casa. 
É bem sabido como a recriação do presépio, inaugurada pelos franciscanos, em Greccio, tinha em vista a cristalização de uma imagem do Menino Jesus, enquanto mediador entre Deus e os homens, apelando à dimensão afetiva e ternurenta que aquela encerra. No entanto, Natália Correia desconstrói esta tradição, colocando em cena um Menino Jesus que se apresenta como uma figura, cujo discurso se pauta por uma acentuada ironia, incompativel com a imagem ancestral do Salvador do Mundo declinada pela Sagrada Escritura. Com efeito, este Menino Jesus não revela qualquer preocupação no que diz respeito à redenção da humanidade, recusando-se, desde logo, a sofrer o martírio na cruz:

- Crescer? Era o que faltava! Para pregarem comigo na cruz?! Nessa é que eu não caio.

Tentei defender o meu ponto de vista:

- Mas se tu não cresceres, nunca mais sais do berço...

- Pois aí é que está. É precisamente esse o meu drama. Se cresço, enfiam-me na cabeça uma coroa de espinhos e põem-me na cruz a verter sangue pelos séculos fora para remir as pulhices dessa canalha que está marimbando para os meus sofrimentos. Se não cresço, prendem-me para sempre neste cochicho de palhinhas onde me obrigam a ser o pretexto para uma comédia de bons sentimentos que só se hospedam nas suas atitudes durante o Natal (CORREIA, 1987, p. 13-14).

A natureza divina do Menino Jesus é também equacionada nesta breve narrativa, na medida em que traduz uma espécie de anulamento da renovação universal em Cristo, que não impede o homem de ultrapassar a sua condição de pecador:

- Coitadinho... estás completamente só...

Ele suspirou:

- É o fado dos deuses.

Este desabafo encheu-me de um respeitoso assombro:

- Ah, então sempre é verdade que tu és um deus?!

Pareceu-me que ele não estava muito convencido disso porque reflectiu antes de responder:

- Bom, confesso que tenho algumas responsabilidades na criação desse mito. Porque eu disse umas coisas diferentes. Mas eles deturparam tudo e foi com essas patranhas que fizeram de mim um deus (CORREIA, 1987, p. 19-20).

Chegados a este ponto, parece-nos que valerá a pena tecer algumas reflexões. Se, de acordo com a tradição, a história da salvação configura-se como um itinerário terreno que atingirá o seu corolário com a segunda vinda de Cristo, a Natividade do Filho de Deus assume um papel fundamental na moldura da redenção da humanidade. Os vários exemplos evocados mostram-nos que a Bíblia continua a funcionar como um macrotexto, na medida em que os autores citados recuperam e revalorizam este episódio bíblico, revestindo-o de novos (ou renovados) significados ou configurações. Se Marie-Elisabeth Henneau e Jean-Pierre Massaut realçaram que, em um contexto da divulgação da Bíblia, a sua leitura pode ter sido, de acordo com as épocas e as circunstâncias ${ }^{4}$, "um privilégio, um direito ou um dever" (HENNEAU; MASSAUT, 1997, p. 415-424, tradução

4 No original: "un privilège, un droit ou un devoir". 
nossa), conduzindo, naturalmente, a mais ou menos profundas alterações na "relação pessoal" com o texto bíblico, os casos aqui respigados atestam a natureza "aberta" da Sagrada Escritura, na medida em que é passivel de múltiplas releituras que permitirão (re)equacionar as questões polarizadas em torno da Redenção da humanidade, evidenciando um fecundo diálogo entre a literatura e os fins últimos.

\section{The nativity of Christ in Portuguese literature: texts and contexts}

Abstract: With the Nativity of Christ as a background, this article seeks to draw attention to the various and diverse re-readings and updates that this narrative was getting to know in Portuguese literature, showing how the Bible is configured as a macro-text.

Keywords: Nativity. Christ. Portuguese literature. Spirituality. Bible.

\section{REFERÊNCIAS}

AGUIAR E SILVA, V. M. P. de. Maneirismo e Barroco na poesia lírica portuguesa. Coimbra: Centro de Estudos Românicos, 1971.

ALMEIDA, C. A. F. de. O presépio na arte medieval. Revista Arqueologia, Porto, separata, 1983.

ALMEIDA, F. de. O país das uvas. Introdução Maria da Graça Orge Martins. Lisboa: Ulisseia, 1987.

BERNARDES, D. Várias Rimas ao Bom Jesus. Edição, introdução e notas Maria Lucília Gonçalves Pires. Porto: CIUHE, 2008.

BERNARDES, J. A. C.; CAMÕES, J. (coord.). Gil Vicente: compêndio. Coimbra: Imprensa da Universidade de Coimbra: Imprensa Nacional, 2018.

BRAGANÇA, J. O. Cardeal D. Henrique. In: Antologia de espirituais portugueses. Lisboa: IN-CM, 1994. p. 315-326.

CAJÃO, L. O outro menino Jesus. Braga: Editora Pax, 1968.

CARDOSO, J. Agiologio Lusitano dos Santos, e Varoens ilustres. Lisboa: Henrique Valente de Oliveira, 1657. t. 2.

CARVAlHO, J. A. de F. A imitatio Christi do cristão e do rei nas Meditações e Homilias dum Cardeal-Rei. In: CONGRESSO INTERNACIONAL IX CENTENÁRIO DA DEDICAÇÃO DA SÉ DE BRAGA, 9, 1990, Braga. Actas [...] . Braga: Universidade Católica Portuguesa: Faculdade de Teologia de Braga: Cabido Metropolitano e Primacial de Braga, 1990. v. III. p. 271-279.

CARVALHO, J. A. de F. Gertrudes de Helfta e Espanha: contribuição para o estudo da história da espiritualidade peninsular nos séculos XVI e XVII. Porto: Inic: Centro de Literatura da Universidade do Porto, 1981.

CARVALHO, J. C. O grande código bíblico entre descodificações e interconexões. Via Spiritus, n. 12, p. 155-171, 2005.

CÉU, Me. M. do. Rellação da vida e morte da serva de Deos a veneravel Madre Elenna da Crus, religiosa no Convento da Esperança desta cidade de Lisboa. Anno 1721. Ed. F. Belo. Lisboa: Quimera, 1993. 
CHORÃO, J. B. Poesia de ausência e de presença. In: Um século de cultura católica em Portugal. Lisboa: Laikos, 1984.

CIRLOT, V.; GARÍ, B. La mirada interior: escritoras místicas y visionarias en la Edad Media. Madrid: Siruela, 2008.

CORREIA, N. Onde está o Menino Jesus? Lisboa: Edições Rolim, 1987.

CRUZ, Fr. A. da. Sonetos e elegias. Estudo, estabelecimento crítico do texto e notas A. G. Rafael. Lisboa: Hiena Editora, 1994.

DELUMEAU, J. Le péché et la peur: la culpabilisation en Occident (XIII-XVIII siècles). Paris: Fayard, 1983.

DIAS, A. Laudes \& Cantigas Espirituais. Coligidas, anotadas e comentadas por M. Martins. Roriz-Negrelos: Mosteiro de Singeverga, 1951.

D'OliVEIRA, A. C. Redondilhas. Porto: Livraria Figueirinhas, 1948.

ESPERANÇA, Fr. M. da. Historia Seraphica da Ordem dos Frades menores da provincia de Portugal. Segunda parte, que conta os seus progressos no estado de três custodias, principio da província e reforma observante. Lisboa: por Antonio Craesbeeck de Melo, 1666. pt. 2.

ESTAÇO, B. Cinco sonetos do natal de Jesus. Seleção e nota introdutória de J. de C. Osório. Lisboa: O Mundo do Livro, 1958.

ESTAÇO, B. Sonetos, canções, eglogas e outras rimas. Coimbra: Officina de Diogo Gomez Loureiro, 1604.

FERNANDES, M. de L. C. Espiritualidade (Época Moderna). In: AZEVEDO, C. M. de (dir.). Dicionário de História Religiosa de Portugal. Lisboa: Círculo de Leitores, 2000. v. 2, p. 187-193.

FERREIRA, A. M. Espiritualidade. III. Época Contemporânea. In: AZEVEDO, C. M. de (dir.). Dicionário de História Religiosa de Portugal. Lisboa: Círculo de Leitores, 2001. t. IV, p. 382-388.

FRYE, N. The Great Code: the Bible and literature. San Diego: Harcourt, 2002.

GAMA, S. da. Pelo sonho é que vamos. Lisboa: Portugália Editora, 1953.

GAMA, S. da. Serra-Mãi. Lisboa: Portugália Editora, 1945.

HENNEAU, M.-E.; MASSAUT, J.-P. Lire la Bible: un privilège, un droit ou un devoir? In: Homo Religiosus. Hommage à Jean Delumeau. Paris: Fayard, 1997. p. 415-424.

HENRIQUE, Card. D. Meditações e Homílias sobre alguns Mysterios da Vida de Nosso Redemptor e sobre alguns Lugares do Sancto Evangelho que fez o Sereníssimo e Reverentíssimo Cardeal D. Anrique \&c. por sua Particular Deuação. Lisboa: António Ribeiro, 1577.

LA ROCCA, S. L'Enfant Jésus. Histoire et anthropologie d'une dévotion dans l'Occident chrétien. Toulouse: Presses Universitaires du Mirail, 2007.

MARTINS, M. Natal franciscano. Brotéria, v. XLV, n. 6, p. 565-581, 1947.

MENDES, P. A. Entre a ascese e a doçura: as Meditações e Homílias sobre alguns Mysterios da Vida de Nosso Redemptor e sobre alguns Lugares do Sancto Evangelho do Cardeal D. Henrique. In: DIMAS, S.; EPIFÂNIO, R.; LÓIA, L. (coord.). Redenção e escatologia: estudos de Filosofia, Religião, Literatura e Arte na Cultura Portuguesa. Lisboa: Universidade Católica Editora, 2017. v. II, t. 1, p. 189-203. 
MENDES, P. A. Paradigmas de papel: a escrita e a edição de "Vidas" de santos de "Vidas" devotas em Portugal (séculos XVI-XVIII). Porto: Citcem, 2017.

MORUJÃO, I. Por trás da grade: poesia conventual feminina em Portugal (séculos XVI-XVIII). Lisboa: Imprensa Nacional-Casa da Moeda, 2013.

MOURA, V. G. (org.). Gloria in Excelsis Deo. Histórias Portuguesas de Natal. Porto: Público, 2003.

MOURÃO-FERREIRA, D. Cancioneiro do Natal. Lisboa: Verbo, 1971.

PIRES, M. L. G. A infância de Cristo na poesia de Baltasar Estaço. Via Spiritus, n. 17, p. 47-57, 2010.

PIRES, Pe. V. Liçam espiritual do nascimento de Christo Nosso Senhor, para a noute do Natal. Roma: Diogo Varesi, 1675.

SANDMANN, M. "Onde está o Menino Jesus?" Natália Correia visita Alberto Caeiro. Letras, Curitiba, n. 43, p. 121-127, 1994.

SANTOS, Z. C. Fonti e ricerche per la storia della santità in Portogallo nel Seicento. Sanctorum, n. 10, p. 143-158, 2013.

SANTOS, Z. C. Literatura religiosa (Época Moderna). In: AZEVEDO, C. M. de (dir.). Dicionário de História Religiosa de Portugal. Lisboa: Círculo de Leitores, 2000. v. 3., p. 125-130.

SANTOS OTERO, A. de los. Los Evangelios Apocrifos. 2. ed. Madrid: La Editorial Catolica, 1963. (Colección de Textos Griegos y Latinos).

TEXTOS PARA O NATAL. Cadernos F.A.O.J., n. 11, 1979.

VIANA, A. M. C. Retábulo para um intimo Natal. Braga: Editora Pax, 1980.

VORAGINE, J. de. La Légende Dorée. Tradução J.-B-M. Roze. Paris: Flammarion, 1967. v. 1. 